\title{
Eigensystem Synthesis for Active Flutter Suppression on an Oblique-Wing Aircraft
}

Gurbux S. Alag, John J. Burken, and Glenn B. Gilyard 


\section{Eigensystem Synthesis for Active Flutter Suppression on an Oblique-Wing Aircraft}

Gurbux S. Alag

Western Michigan University, Kalamazoo, Michigan

John J. Burken and Gienn B. Gilyard

Ames Research Center, Dryden Flight Research Facility, Edwards, California

\section{N/SA}

National Aeronautics and

Space Administration

Ames Research Center

Dryden Flight Research Facility

Edwards, California 93523-5000 


\author{
Gurbux S. Alag* \\ Western Michigan University \\ $\mathrm{Kal}$ amazoo, Michigan \\ and \\ John J. Burken** and Glenn B. Gilyard** \\ NASA Ames Research Center \\ Dryden Flight Research Facility \\ Edwards, Cal ifornia
}

Abstract

The application of the eigensystem synthesis technique to place the closed-loop eigenvalues and shape the closed-loop eigenvectors has not been practical for active flutter suppression. primarily because of the availability of only one control surface (aileron) for flutter suppression. The oblique-wing aircraft, because of its configuration, provides two independent surfaces (left and right ailerons), making the application of eigensystem synthesis practical. This paper presents the application of eigensystem synthesis using output feedback for the design of an active flutter suppression system for an oblique-wing aircraft. The results obtained are compared with those obtained by linear quadratic Gaussian techniques.

\section{Symbols}

A

B

c

I

K

L

L partitioned matrix of specified components of $\left(\lambda_{j} I-A\right)^{-1_{B}}$

$\bar{L} \quad$ complex conjugate transpose of $L$

M partitioned matrix of unspecified components of $\left(\lambda_{i} I-A\right)^{-1} B$

u input vector

$\checkmark \quad$ eigenvector matrix

$v_{\mathfrak{j}} \quad c l o s e d-100 p$ eigenvector

$v_{j}^{a}, v_{i}^{d} \quad$ achievable and desired eigenvectors, respectively

$v_{j}^{*} \quad$ complex conjugate of $v_{i}$

$x \quad$ state vector

*Associate Professor, Electrical Engineering Department. Member AIAA.

**Aerospace Engineer. $y$

$\lambda_{i}, \lambda_{\mathbf{i}}^{*}$

$\underline{\sigma}$

minimum singular value of the return difference matrix

\section{Introduction}

The U.S. Navy and NASA are currently involved in the design and development of an unsymmetricskew-wing aircraft capable of $65^{\circ}$ wing sweep and flight at Mach 1.6. Such a unique configuration exhibits aeroelastic behavior distinctly different than that of straight, swept-back, or swept-forward wings and has a potential for poor modal response characteristics. The most serious result of such characteristics can be flutter, an unstable motion caused by an interaction between structural vibrations and aerodynamic forces. ${ }^{1}$ Active suppression of aerodynamic wing flutter can result in substantial weight savings and increases in performance compared with passive methods such as increased structural stiffness and mass balancing.

The synthesis of modal control systems for unsymmetric aircraft requires considerably more states than are necessary for symmetric configurations because all degrees of freedom must be adequately represented in a single formulation. The model representing the aircraft must include rigid-body modes, flexible modes, unsteady aerodynamics, actuators, and gust states. Control 1 aws have been formulated for active flutter control using the standard linear quadratic Gaussian (LQG) procedure;2-4 the synthesized optimal feedback control laws are of the same order as the aircraft plant. Practicalizing the control law requires order reduction by techniques such as transfer function matching, modal truncation, and residualization. $5-7$

To investigate modal control synthesis strategies for an oblique-wing configuration, a generic skew-wing aircraft model was developed for $45^{\circ}$ wing skew at a flight condition of Mach 0.70 at $10,000 \mathrm{ft}$ altitude. At this flight condition the aircraft has an unstable flutter mode. An active implementable flutter control 1 aw was developed 8 using the LQG design technique and modal residualization to reduce the order of the controller. However, this method increased the order of response of the closed-10op system as compared with that of the open-loop system and degraded modal control characteristics. 
Eigensystem synthesis procedures are suitable for flight control system design because they do not increase the order of the system. Also, the difficulty in incorporating specifications such as damping, frequency, and decoupling within a quadratic performance index makes the eigensystem synthesis procedure a promising design alternative. The performance specifications can be interpreted in terms of desired closed-loop eigenvalues and eigenvectors. Moore ${ }^{9}$ and others have shown how feedback can be used to place closedloop eigenvalues and shape closed-loop eigenvectors. References 10 to 12 successfully demonstrate the use of an eigenstructure assignment procedure for aircraft control system design.

The eigensystem synthesis technique using output feedback to place closed-loop eigenvalues and shape closed-loop eigenvectors has not been used for active flutter suppression, primarily because of the availability of only one control surface for flutter suppression, making eigenvector shaping impractical. The oblique-wing aircraft, because of its configuration, provides two independent control surfaces (left and right ailerons) and makes the application of eigensystem synthesis practical.

This paper presents the application of eigensystem synthesis to the design of an active flutter suppression system for a generic model of an oblique-wing aircraft. The results obtained are compared with those obtained by LOG techniques.

\section{Flutter Suppression Using Eigenstructure}

The generic oblique-wing aircraft aerostructural model used in the system synthesis process is a simple beam representation of the fuselage and wing. The aerodynamic model was developed by superimposing aero panels over the beams, as shown in Fig. 1. The aircraft modal characteristics were developed using NASTRAN analysis. At the sweep configuration $\left(45^{\circ}\right)$ and flight condition (Mach $0.70,10,000 \mathrm{ft}$ ) selected, the unaugmented aircraft has a flutter mode characterized as primarily wing bending. Because the intent of this paper is to demonstrate a design synthesis process, the model order was reduced considerably; the final model contained a rigid-body (primarily pitch) mode along with three elastic modes. The model reduction process did not significantly affect the flutter mode characteristics. Details of the aircraft model formulation are given in Ref. 8.

The aircraft design model includes the 1 inearized form of the unsteady aerodynamics, actuators, and gust model dynamics and can be represented as

$$
\begin{aligned}
& \dot{x}=A x+B u \\
& y=C x
\end{aligned}
$$

where $x$ is a $24 \times 1$ state vector, $y$ is a $5 \times 1$ output vector, $u$ is a $2 \times 1$ input vector, and $A, B$, and $C$ are the plant, control, and output matrices, respectively, of suitable dimensions. The 24 states include the rigid-body mode, flexible mode deflections, flexible mode rates, unsteady aerodynamic states, actuator deflection and rate states, and wind gust states. Eight states result from the retained structural modes, eight from the two-lag-term set of approximated unsteady aerodynamics, six from the two actuators, and two from the gust model. The five outputs consist of pitch angle, pitch rate, and three accelerations: center of gravity and right and left wingtips. The two inputs are right and left aileron deflections.

For the system under consideration, the following conditions hold: 11

1. A maximum of five closed-loop eigenvalues $c$ an be assigned arbitrarily with the stipulation that if $\lambda_{i}$ is a complex closed-loop eigenvalue,

its complex conjugate $\lambda_{i}^{*}$ must al so be a closedloop eigenvalue.

2. A maximum of five eigenvectors $c$ an be altered. If the shape of a complex eigenvector $v_{j}$ is altered, its complex conjugate $v_{j}^{*}$ must be altered in the same way.

3. For each eigenvector whose shape is altered, a maximum of two eigenvector elements can be chosen arbitrarily.

4. Achievable eigenvectors must 1 ie in the subspace spanned by the columns of $\left(\lambda_{j} I-A\right)^{-l_{B}}$ of dimension two, which is the number of independent control variables. A desired eigenvector $v_{j}^{d}$ will in general not reside in the prescribed subspace and cannot be achieved. The optimal achievable eigenvector $v_{i}^{a}$ is obtained by the orthogonal projection of $v_{i}^{d}$ onto the subspace spanned by $\left(\lambda_{i} I-A\right)^{-1} B$.

Given the system of equations (1) and (2) and assuming an output feedback, the control input $u$ is given by

$$
u=k y
$$

where $K$ is the gain matrix of dimension $2 \times 5$. For the closed-loop system, the following relationship holds:

$$
(A-B K C) v_{i}=\lambda_{i} v_{i}
$$

where $v_{i}$ is a closed-loop eigenvector and $\lambda_{i}$ a closed-loop eigenvalue; or

$$
\left(\lambda_{i} I-A\right) v_{j}=-B K C v_{i}=B M_{j}
$$

where

$$
M_{i}=-K C v_{i}
$$

In general, the desired eigenvector $v_{i}^{d}$ does not reside in the achievable subspace, and an approxi- 
mate solution by methods of orthogonal projection can be obtained.13

\section{If}

$$
L_{i}=\left(\lambda_{j} I-A\right)^{-1} B
$$

then the achievable eigenvector $v_{i}^{a}$ is given by

$$
v_{i}^{a}=L_{j}\left(\bar{L}_{i}^{-} L_{i}\right)^{-1} \bar{L}_{i} v_{i}^{d}
$$

and the gain $K$ is given by

$$
K=-M(C V)^{\dagger}
$$

where the superscript + denotes pseudoinverse, $\bar{L}_{\dot{j}}$ is the complex conjugate tranpose of $\mathrm{L}_{i}$, and

$$
\begin{aligned}
& M=\left[\begin{array}{llll}
M_{1} & M_{2} & \ldots & M_{n}
\end{array}\right] \\
& V=\left[\begin{array}{llll}
v_{1}^{a} & v_{2}^{a} & \ldots & v_{n}^{a}
\end{array}\right]
\end{aligned}
$$$$
\text { Results }
$$

The control law synthesized by the method outlined was applied to the design of an active flutter suppression controller for an oblique-wing aircraft. A generic $45^{\circ}$ wing-skew structural model was developed to simulate flutter at a subsonic flight condition of Mach 0.70 and an altitude of $10,000 \mathrm{ft}$.

Table 1 gives the eigenvalues of the open-loop aircraft model. The unstable eigenvalue pair at this flight condition $(0.5 \pm 14.37 i)$ represents primarily wing bending.

The design objective was to stabilize the aircraft without exceeding the specified rootmean-square (rms) control activity so that saturation would not occur. Based on actuator limitations, the rms deflection of the aileron was limited to $5^{\circ}$ and the deflection rate to $30 \mathrm{deg} / \mathrm{sec}$. In addition to stabilizing the aircraft with low surface activity, it is required that the controller be robust. The controller considered here is multi-input, multi-output: the right and left wing control surfaces are independent of each other because of the unsymmetric nature of the aircraft. Robustness of the multiloop control system is evaluated by using the singular values of the return difference matrix.14

The process of selecting desired closed-loop eigenvalues and eigenvectors for the case under consideration presents a problem. The selection of desired eigenvalues and eigenvectors normally is based on engineering judgment and requires a clear insight into physical aspects of the plant being controlled. Most of the physical insight for the flutter problem is lost in the process of model reduction from the original large dimensions to the 24th-order model developed for the control system synthesis process.
A time-consuming and arbitrary method for the selection of eigenvectors did lead to stabilization of the aircraft. Another method, using closed-10op eigenvalues and eigenvectors obtained through LQG design assuming full-state feedback, was used to obtain a stable closed-loop system. The closed-loop eigenvalues and eigenvectors obtained by this method were selected as the desired eigenvalues and eigenvectors for the eigensystem synthesis process.

Table 2 gives the desired locations of the five closed-loop eigenvalues as well as the desired eigenvectors. Five eigenvalues were located, including the unstable flutter mode, at the desired location. The achieved eigenvectors are given in Table 2. The feedback gain $K$ was evaluated based on the achieved eigenvalues and eigenvectors. The values of $k$ and the closedloop eigenvalues of the aircraft are also indicated in Table 2.

Table 3 gives the comparative description of the rins values of response to gust input for both the LQG design 8 (seventh-order controller) and the controller designed using eigensystem synthesis. The eigensystem synthesis rms values for the surface deflections and rates are within the prescribed range and compare favorably with those obtained by the other method.

The controller developed by this method ( $K$ is a $2 \times 5$ matrix) is extremely simple to implement. In comparison, the LQG design technique uses a full-order controller (the order being the same as that of the plant). Even a reduced-order controller is difficult to implement and increases the order of the system.

However, this eigensystem synthesis approach compromises robustness. Stability robustness of multi-input, multi-output feedback control systems is characterized by the minimum singular value of the return difference matrix of the plant input or output.14 Figure 2 shows the plots of the minimum singular values $\sigma$ for the controller developed in this paper and the full-state feedback controller developed using the LQG technique. 8 A degradation in robustness is evident from the plot. However, the reduced-order controller is not as robust as the one designed using the eigensystem procedure, as is evident from Fig. 2 .

\section{Conclusions}

An implementable flutter controller for a $45^{\circ}$-skew oblique-wing aircraft mathematical model was designed using the eigensystem synthesis technique. The controller does not increase the order of the system and is extremely simple to implement, whereas the LQG design technique uses a full-order controller, is difficult to implement, and increases the order of the system. Work is in progress to improve stability margins by using constrained optimization techniques to shape the singular value spectrum.15 A standard performance index is minimized while trying to satisfy minimum singular value constraints at the plant input or output, or both. 
References.

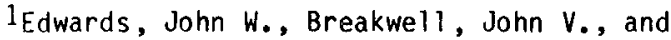
Bryson, Arthur E., "Active Flutter Control Using Generalized Unsteady Aerodynamic Theory," J. Guidance Control, vol. 1, no. 1, Jan.-Feb. 1978, pp. 32-40.

2Adams, William M., Jr., and Tiffany, Sherwood H., "Design of a Candidate Flutter Suppression Control Law for DAST ARW-2," AIAA-83-2221, Aug. 1983.

3Mahesh, J.K., Stone, C.R., Garrard, W.L., and Dunn, H.J., "Control Law Synthesis for Flutter Suppression Using Linear Quadratic Gaussian Theory," J. Guidance Control, vol . 4, no. 4, 1981 , pp. 415-422.

4Mukhopadhyay, V., Newson, J.R., and Abel, I., "Reduced-Order Optimal Feedback Control Law Synthesis for Flutter Suppression," J. Guidance Control, vol. 5, no. 4, 1982, pp. 389-395.

5Newsom, Jerry R., "A Method for Obtaining Practical Flutter Suppression Control Laws Using Results of Optimal Control Theory," NASA TP-1471, 1979.

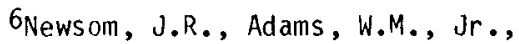
Mukhopadhyay, V., Tiffany, S.H., and Abel, I., "Active Controls: A Look at Analytical Methods and Associated Tools," NASA TM-86269, 1984.

7Mahesh, J.K., Stone, C.R., Garrard, W.L., and Hausman, P.D., "Active Flutter Control for Flexible Vehicles," NASA CR-159160, 1979.
BBurken, John J., Alag, Gurbux S., and Gilyard, Glenn B., "Aeroel astic Control of Oblique-Wing Aircraft," NASA TM-86808, 1986.

9Moore, B.C., "On the Flexibility offered by Full State Feedback in Multivariable Systems Beyond Closed Loop Eigenvalue Assignment," IEEE Trans. Automat. Control, vol. 21, Oct. 1976, pp. 689-692.

10Cunningham, Thomas B., "Eigenspace Selection Procedures for Closed Loop Response Shaping With Modal Control," Proc. 19th IEEE Conference on Decision and Control, Dec. 1980, pp. 178-186.

${ }^{11}$ Andry, A.N., Shapiro, E.Y., and Chung, J.C., "Eigenstructure Assignment for Linear Systems," IEEE Trans. Aerospace Electron. Systems, Sept. 1983, pp. 711-729.

12Sobel, K.M., and Shapiro, E.Y., "Application of Eigensystem Assignment to Lateral Translation and Yaw Pointing Flight Control," Proc. 23rd IEEE Conference on Decision and Control, Las Vegas, Nevada, Dec. 1984, pp. 1423-1438.

13 Harvey, C.A., Stein, G., and Doyle, J.C., "Optimal Linear Control," Report ONR CR 215-238-2, 1977.

14Ly, Uy-Loi, "Robustness Analysis of a Multiloop Flight Control System," AIAA-83-2189, Aug. 1983.

15Mukhopadhyay, V., "Stability Robustness Improvement Using Constrained Optimization Techiques," AIAA-85-1931-CP, Aug. 1985.

Table 1 open-loop eigenvalues

$\begin{array}{r}-0.0000+0.0000 i \\ -0.4187+0.0000 i \\ -0.4229+0.0000 i \\ -4.2075+0.0000 i \\ -0.1612+5.0036 i \\ -0.1612-5.0036 i \\ -1.9397+14.0551 i \\ -1.9397-14.0551 i \\ 0.5011+14.3649 i \\ 0.5011-14.3649 i \\ -20.0000+0.0000 i \\ -20.0000+0.0000 i \\ -30.8526+0.0000 i \\ -35.1822+0.5223 i \\ -35.1822-0.5223 i \\ -37.1170+3.5647 i \\ -37.1170-3.5647 i \\ -39.6927+0.6080 i \\ -39.6927+0.6080 i \\ -41.3346+0.0000 i \\ -36.4000+37.1354 i \\ -36.4000-37.1354 i \\ -36.4000+37.1354 i \\ -36.4000-37.1354 i \\ \hline-\end{array}$


Table 2 Eigensystem variables

\begin{tabular}{|c|c|c|c|c|c|}
\hline \multicolumn{5}{|c|}{ Desired eigenvectors (from LQG method) } & Desired eigenvalues \\
\hline $\begin{array}{r}3.9999 \\
0.0000 \\
0.0000 \\
0.0000 \\
-0.0010 \\
0.0000 \\
0.0000 \\
0.0000 \\
0.0746 \\
0.0612 \\
-0.0247 \\
0.0829 \\
-0.0699 \\
-0.0578 \\
0.0015 \\
-0.1024 \\
0.0000 \\
0.0000 \\
0.0000 \\
0.0000 \\
0.0000 \\
0.0000 \\
0.0000 \\
0.0000\end{array}$ & $\begin{array}{r}0.0438+0.0049 i \\
-0.0317+0.0018 i \\
0.0011+0.0001 i \\
0.0047+0.0001 i \\
-0.0349+0.2177 i \\
-0.0017-0.1588 i \\
-0.0009+0.0057 i \\
-0.0014+0.0236 i \\
2.8445+16.2616 i \\
1.9139+5.3855 i \\
-7.3179-74.9682 i \\
0.9809-29.5832 i \\
-2.6257-15.7088 i \\
-1.6892-3.9659 i \\
6.1769+73.0802 i \\
-1.9195+26.9120 i \\
0.0000+0.0001 i \\
-0.0003+0.0001 i \\
-0.0006-0.0016 i \\
0.0000+0.0000 i \\
0.0000+0.0000 i \\
-0.0001-0.0001 i \\
0.0000+0.0000 i \\
0.0000+0.0000 i\end{array}$ & $\begin{array}{r}0.0438-0.0049 i \\
-0.0317-0.0018 i \\
0.0011-0.0001 i \\
0.0047-0.0001 i \\
-0.0349-0.2177 i \\
-0.0017+0.1588 i \\
-0.0009-0.0057 i \\
-0.0014=0.0236 i \\
2.8445-16.2616 i \\
1.9139-5.3855 i \\
-7.3179+74.9682 i \\
0.9809+29.5832 i \\
-2.6257+15.7088 i \\
-1.6892+3.9659 i \\
6.1769-73.0802 i \\
-1.9195-26.9120 i \\
0.0000-0.0001 i \\
-0.0003-0.0001 i \\
-0.0006+0.0016 i \\
0.0000-0.0000 i \\
0.0000-0.0000 i \\
-0.0001+0.0001 i \\
0.0000-0.0000 i \\
0.0000-0.0000 i\end{array}$ & $\begin{array}{r}0.0015+0.0007 i \\
-0.0245+0.0089 i \\
0.0023+0.0004 i \\
-0.0004+0.0004 i \\
-0.0104+0.0216 i \\
-0.1154-0.3565 i \\
-0.0075+0.0330 i \\
-0.0054-0.0065 i \\
-6.5976-0.9621 i \\
2.4618+6.5556 i \\
2.4855-3.2472 i \\
10.8184-32.7421 i \\
7.1162+3.8695 i \\
-2.0765-5.6525 i \\
-2.6786-0.0123 i \\
-12.8369+31.1018 i \\
0.0004+0.0003 i \\
-0.0050+0.0055 i \\
-0.0766-0.0740 i \\
0.0009-0.0001 i \\
0.0016+0.0130 i \\
-0.1878+0.0159 i \\
0.0000-0.0000 i \\
0.0000-0.0000 i\end{array}$ & $\begin{array}{r}0.0015-0.0007 i \\
-0.0245-0.0089 i \\
0.0023-0.0004 i \\
-0.0004-0.0004 i \\
-0.0104-0.0216 i \\
-0.1154+0.3565 i \\
-0.0075-0.0330 i \\
-0.0054+0.0065 i \\
-6.5976+0.9621 i \\
2.4618-6.5556 i \\
2.4855+3.2472 i \\
10.8184+32.7421 i \\
7.1162-3.8695 i \\
-2.0765+5.6525 i \\
-2.6786+0.0123 i \\
-12.8369-31.1018 i \\
0.0004-0.0003 i \\
-0.0050-0.0055 i \\
-0.0766+0.0740 i \\
0.0009+0.0001 i \\
0.0016-0.0130 i \\
-0.1878-0.0159 i \\
0.0000+0.0000 i \\
0.0000+0.0000 i\end{array}$ & $\begin{array}{l}-0.0003+0.0000 i \\
-0.2355-5.0020 i \\
-0.2355+5.0020 i \\
-0.5041-14.3657 i \\
-0.5041+14.3657 i\end{array}$ \\
\hline \multicolumn{5}{|c|}{ Achieved eigenvectors } & $\begin{array}{c}\text { Achieved closed-loop } \\
\text { eigenvalues }\end{array}$ \\
\hline $\begin{array}{r}3.9999 \\
0.0000 \\
0.0000 \\
0.0000 \\
-0.0010 \\
0.0000 \\
0.0000 \\
0.0000 \\
0.0746 \\
0.0612 \\
-0.0247 \\
0.0829 \\
-0.0699 \\
-0.0578 \\
0.0015 \\
-0.1024 \\
0.0000 \\
0.0000 \\
0.0000 \\
0.0000 \\
0.0000 \\
0.0000 \\
0.0000 \\
0.0000\end{array}$ & $\begin{array}{r}0.0438+0.0049 i \\
-0.0317+0.0018 i \\
0.0011+0.0001 i \\
0.0047+0.0001 i \\
-0.0349+0.2177 i \\
-0.0017-0.1588 i \\
-0.0009+0.0057 i \\
-0.0014+0.0236 i \\
2.8445+16.2616 i \\
1.9139+5.3855 i \\
-7.3179-74.9682 i \\
0.9809-29.5832 i \\
-2.6257-15.7088 i \\
-1.6892+3.9659 i \\
6.1769+73.0802 i \\
-1.9195+26.9120 i \\
0.0000+0.0001 i \\
-0.0003+0.0001 i \\
-0.0006-0.0016 i \\
0.0000+0.0000 i \\
0.0000+0.0000 i \\
-0.0001-0.0001 i \\
0.0000+0.0000 i \\
0.0000+0.0000 i\end{array}$ & $\begin{array}{r}0.0438-0.0049 i \\
-0.0317-0.0018 i \\
0.0011-0.0001 i \\
0.0047-0.0001 i \\
-0.0349-0.2177 i \\
-0.0017+0.1588 i \\
-0.0009-0.0057 i \\
-0.0014-0.0236 i \\
2.8445-16.2616 i \\
1.9139-5.3855 i \\
-7.3179+74.9682 i \\
0.9809+29.5832 i \\
-2.6257+15.7088 i \\
-1.6892+3.9659 i \\
6.1769-73.0802 i \\
-1.9195-26.9120 i \\
0.0000-0.0001 i \\
-0.0003-0.0001 i \\
-0.0006+0.0016 i \\
0.0000-0.0000 i \\
0.0000=0.0000 i \\
-0.0001+0.0001 i \\
0.0000-0.0000 i \\
0.0000-0.0000 i\end{array}$ & $\begin{array}{r}0.0015+0.0007 i \\
-0.0245+0.0089 i \\
0.0023+0.0004 i \\
-0.0004+0.0004 i \\
-0.0104+0.0216 i \\
-0.1154-0.3565 i \\
-0.0075+0.0330 i \\
-0.0054-0.0065 i \\
-6.5976-0.9621 i \\
2.4618+6.5556 i \\
2.4855-3.2472 i \\
10.8184-32.7421 i \\
7.1162+3.8695 i \\
-2.0765-5.6525 i \\
-2.6786-0.0123 i \\
-12.8369+31.1018 i \\
0.0004+0.0003 i \\
-0.0050+0.0055 i \\
-0.0766-0.0740 i \\
0.0009-0.0001 i \\
0.0016+0.0130 i \\
-0.1878+0.0159 i \\
0.0000-0.0000 i \\
0.0000-0.0000 i\end{array}$ & $\begin{array}{r}0.0015-0.0007 i \\
-0.0245-0.0089 i \\
0.0023-0.0004 i \\
-0.0004-0.0004 i \\
-0.0104-0.0216 i \\
-0.1154+0.3565 i \\
-0.0075-0.0330 i \\
-0.0054+0.0065 i \\
-6.5976+0.9621 i \\
2.4618-6.5556 i \\
2.4855+3.2472 i \\
10.8184+32.7421 i \\
7.1162-3.8695 i \\
-2.0765+5.6525 i \\
-2.6786+0.0123 i \\
-12.8369-31.01018 i \\
0.0004-0.0003 i \\
-0.0050-0.0055 i \\
-0.0766+0.0740 i \\
0.0009+0.0001 i \\
0.0016-0.0130 i \\
-0.1878-0.0159 i \\
0.0000+0.0000 i \\
0.0000+0.0000 i\end{array}$ & $\begin{array}{l}-0.0003+0.0000 i^{a} \\
-0.4187+0.0000 i \\
-0.4229+0.0000 i \\
-3.6775+0.0000 i \\
-0.2355+5.0020 i a \\
-0.2355-5.0020 i a \\
-1.3818+12.9445 i \\
-1.3818-12.9445 i \\
-0.5041+14.3657 i a \\
-0.5041-14.3657 i a \\
-23.1705+0.0000 i \\
-21.2819+13.9913 i \\
-21.2819-13.9913 i \\
-34.5807+1.0410 i \\
-34.5807-1.0410 i \\
-39.5120+1.8798 i \\
-39.5120-1.8798 i \\
-39.9263+0.0000 i \\
-30.2236+29.6354 i \\
-30.2236-29.6354 i \\
-49.9016+16.2655 i \\
-49.9016-16.2655 i \\
-33.5655+41.6373 i \\
-33.5655-41.6373 i\end{array}$ \\
\hline
\end{tabular}

Eigensystem feedback gain matrix, $K$

$\begin{array}{lllll}0.0000 & 0.0004 & -0.0006 & -0.0001 & 0.0002\end{array}$

$\begin{array}{lllll}0.0000 & 0.0009 & -0.0010 & -0.0001 & -0.0001\end{array}$

a See desired eigenvalues. 
Table 3 Root-mean-square responses at flutter conditions

\begin{tabular}{|c|c|c|c|c|}
\hline & \multicolumn{2}{|c|}{ Right wing } & \multicolumn{2}{|c|}{ Left wing } \\
\hline & $\delta$, deg & $\dot{\delta}, \mathrm{deg} / \mathrm{sec}$ & $\delta$, deg & $\dot{\delta}, \mathrm{deg} / \mathrm{sec}$ \\
\hline Full-state feedback & 1.58 & 7.91 & 0.28 & 3.58 \\
\hline $\begin{array}{l}\text { Full-order controller } \\
\text { with Kalman estimator }\end{array}$ & 1.58 & 12.58 & 0.41 & 5.64 \\
\hline $\begin{array}{l}\text { Full-order controller } \\
\text { with robust Kalman } \\
\text { estimator }\end{array}$ & 2.06 & 11.21 & 0.41 & 5.02 \\
\hline $\begin{array}{l}\text { Reduced-order } \\
\text { controller }\end{array}$ & 1.51 & 10.04 & 0.41 & 4.90 \\
\hline $\begin{array}{l}\text { Eigensystem } \\
\text { synthesis }\end{array}$ & 0.62 & 4.81 & 0.69 & 8.46 \\
\hline
\end{tabular}

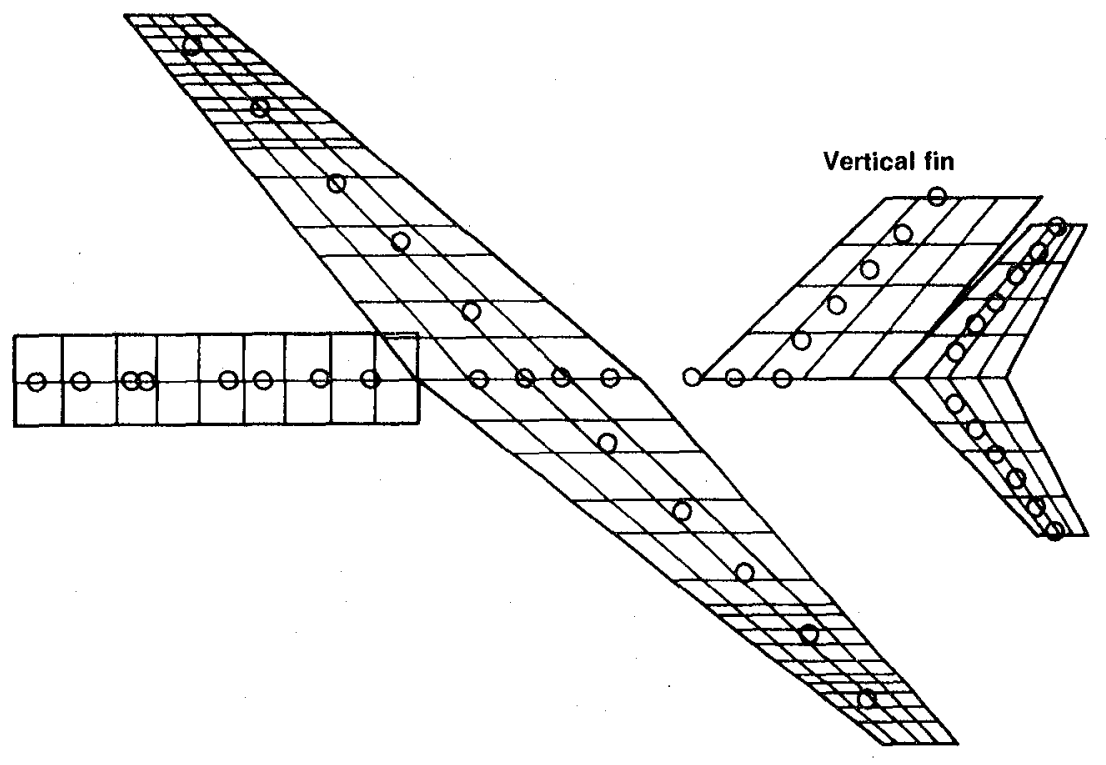

Fig. 1 Generic model (aero panels and node points). Vertical fin shown in $X-Y$ plane.

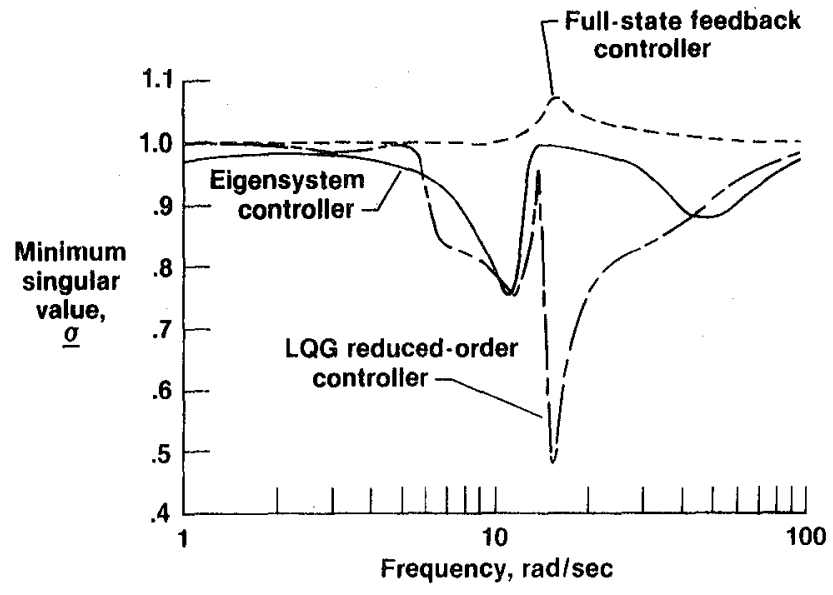

Fig. 2 Minimum singular values of the return difference matrix. 


\begin{tabular}{|c|c|c|c|c|}
\hline \multicolumn{2}{|r|}{$\begin{array}{l}\text { 1. Report No. } \\
\text { NASA TM-88275 }\end{array}$} & 2. Government Accession No. & \multicolumn{2}{|c|}{ 3. Recipient's Catalog No. } \\
\hline \multirow[t]{2}{*}{4} & \multirow{2}{*}{\multicolumn{2}{|c|}{$\begin{array}{l}\text { Tirle and Subtitle } \\
\text { EIGENSYSTEM SYNTHESIS FOR ACTIVE FLUTTER SUPPRESSION } \\
\text { ON AN OBLIQUE-WING AIRCRAFT }\end{array}$}} & \multicolumn{2}{|l|}{$\begin{array}{l}\text { 5. Report Date } \\
\text { August } 1986\end{array}$} \\
\hline & & & \multicolumn{2}{|c|}{ 6. Performing Organization Code } \\
\hline & \multicolumn{2}{|c|}{$\begin{array}{l}\text { Authoris) } \\
\text { Gurbux S. Alag, * John J. Burken, and Glenn B. Gilyard }\end{array}$} & \multicolumn{2}{|c|}{$\begin{array}{l}\text { 8. Performing Organization Report No. } \\
H-1359\end{array}$} \\
\hline \multirow{3}{*}{\multicolumn{3}{|c|}{$\begin{array}{l}\text { 9. Performing Organization Name and Address } \\
\text { NASA Ames Research Center } \\
\text { Dryden Flight Research Facility } \\
\text { P.0. Box } 273 \\
\text { Edwards, CA } 93523-5000\end{array}$}} & \multicolumn{2}{|c|}{$\begin{array}{l}\text { 10. Work Unit No. } \\
\text { RTOP 533-02-91 }\end{array}$} \\
\hline & & & \multicolumn{2}{|c|}{ 11. Contract or Grant No. } \\
\hline \multirow{2}{*}{\multicolumn{3}{|c|}{$\begin{array}{l}\text { 12. Sponsoring Agency Neme and Address } \\
\text { National Aeronautics and Space Administration } \\
\text { Washington, D.C. } 20546\end{array}$}} & \multicolumn{2}{|c|}{$\begin{array}{l}\text { 13. Type of Report and Period Covered } \\
\text { Technical Memorandum }\end{array}$} \\
\hline & & & \multicolumn{2}{|c|}{ 14. Sponsoring Agency Code } \\
\hline \multicolumn{5}{|c|}{$\begin{array}{l}\text { 15. Supplementary Notes Prepared as AIAA-86-2243-CP for presentation at the AIAA Guidance, Navigation, } \\
\text { and Control Conference, Williamsburg, Virginia, August 18-20, 1986. } \\
\text { *Western Młchigan University, Kalamazoo, Michigan }\end{array}$} \\
\hline \multicolumn{5}{|c|}{$\begin{array}{l}\text { of the eigensystem synt } \\
\text { genvalues and shape the c } \\
\text { ical for active flutter s } \\
\text { ilability of only one con } \\
\text { ssion. The oblique-wing } \\
\text { ides two independent sur } \\
\text { che application of eigens } \\
\text { the application of eige } \\
\text { the design of an active } \\
\text { aircraft. The results } \\
\text { inear quadratic Gaussian }\end{array}$} \\
\hline \multicolumn{3}{|c|}{$\begin{array}{l}\text { 7. Koy Words (Suggested by Author(s)) } \\
\text { Active flutter suppression } \\
\text { Ejgellstructure } \\
\text { Obifque-wing aircraft }\end{array}$} & \multicolumn{2}{|c|}{$\begin{array}{l}\text { 18. Distribution Statement } \\
\text { Unclassified - Unl imited } \\
\text { STAR category } 08\end{array}$} \\
\hline 19. & $\begin{array}{l}\text { Security Classif. (of this report) } \\
\text { Unclass ifted }\end{array}$ & $\begin{array}{l}\text { 20. Security Classif. (of this page) } \\
\text { Unclassified }\end{array}$ & $\begin{array}{l}\text { 21. No. of Pages } \\
7\end{array}$ & $\begin{array}{l}\text { 22. Price } \\
\mathrm{A} 02\end{array}$ \\
\hline
\end{tabular}


End of Document 